J. Biosoc. Sci., (2016) 48, S16-S39 (C) Cambridge University Press, 2016. This is an Open Access article, distributed under the terms of the Creative Commons Attribution licence (http:// creativecommons.org/licenses/by/4.0/), which permits unrestricted re-use, distribution, and reproduction in any medium, provided the original work is properly cited.

doi:10.1017/S0021932016000018

\title{
RUMOURS, RIOTS AND THE REJECTION OF MASS DRUG ADMINISTRATION FOR THE TREATMENT OF SCHISTOSOMIASIS IN MOROGORO, TANZANIA
}

\author{
JULIE HASTINGS ${ }^{1}$ \\ College of Business, Arts and Social Sciences, Brunel University, UK
}

\begin{abstract}
Summary. In 2008 in Morogoro region, Tanzania, mass drug administration (MDA) to school-aged children to treat two neglected tropical diseases (NTDs) - urinary schistosomiasis and soil-transmitted helminths - was suspended by the Ministry of Health and Social Welfare after riots broke out in schools where drugs were being administered. This article discusses why this biomedical intervention was so vehemently rejected, including an eyewitness account. As the protest spread to the village where I was conducting fieldwork, villagers accused me of bringing medicine into the village with which to 'poison' the children and it was necessary for me to leave immediately under the protection of the Tanzanian police. The article examines the considerable differences between biomedical and local understandings of one of these diseases, urinary schistosomiasis. Such a disjuncture was fuelled further by the apparent rapidity of rolling out MDA and subsequent failures in communication between programme staff and local people. Rumours of child fatalities as well as children's fainting episodes and illnesses following treatment brought about considerable conjecture both locally and nationally that the drugs had been either faulty, counterfeit, hitherto untested on humans or part of a covert sterilization campaign. The compelling arguments by advocates of MDA for the treatment of NTDs rest on the assumption that people suffering from these diseases will be willing to swallow the medicine. However, as this article documents, this is not always the case. For treatment of NTDs to be successful it is not enough for programmes to focus on economic and biomedical aspects of treatment, rolling out 'one size fits all' programmes in resource-poor settings. It is imperative to develop a biosocial approach: to consider the local social, biological, historical, economic and political contexts in which these programmes are taking place and in which the intended recipients of treatment live their lives. If this is not done, the world's poor will continue to be neglected.
\end{abstract}

${ }^{1}$ Email: Julie.hastings@brunel.ac.uk 


\section{Introduction}

Over the past 15 years campaigners have built a convincing case to develop national programmes for the integrated control of neglected tropical diseases (NTDs) in sub-Saharan Africa. This primarily involves community-based mass drug administration (MDA) of preventive chemotherapy. Numerous optimistic articles have been published by prominent advocates of mass treatment for NTDs, declaring, for example, that 'Controlling neglected diseases would be crucial to achieving seven of the eight MDGs' (Fenwick et al., 2005, p. 1029). Proponents have employed increasingly colourful and emotive language. In 2005, rapid impact interventions of NTDs were said to 'benefit the poor' (Molyneux et al., 2005, p. 63), and four years later treatment was said to be a way of 'rescuing' them (Hotez et al., 2009, p. 1570). It has even been argued that treating NTDs is an effective US foreign policy strategy for 'waging peace' (Hotez \& Thompson, 2009).

The rationale for MDA rests upon several points, the central one being that there are a number of effective, cheap and donated drugs that can easily be administered to affected populations making the treatment of NTDs - such as schistosomiasis - one of the 'best buys' in global public health (SCI, 2011). Such is the apparent safety of the drugs and the ease of their administration that non-medically trained staff, such as teachers and village drug distributors, need only attend a 'short course' (ibid.) - usually a one-day training session - before they can administer them. In endemic areas where prevalence is greater than $50 \%$, the aim is to treat the whole population during mass treatment programmes, with a required uptake of $75 \%$ for treatment to be considered successful from an epidemiological standpoint. Administering drugs to people, including children, who might not even be infected raises an ethical dilemma that seems largely to have been overlooked by exponents of MDA.

The compelling arguments for the mass administration of anthelmintic drugs to treat NTDs focus on the biomedical rationale for treatment, specifically the drugs' efficacy, safety and cost-effectiveness. While these are of course crucial considerations in the provision of free treatment for people suffering from NTDs, they do not take into consideration the very people they set out to help and the context in which they live their lives. The biomedical rationale rests on the assumption that people will be willing to swallow these drugs for the treatment of these diseases. However, the research presented in this article clearly demonstrates that this is not always the case. It shows how a 'one size fits all' policy of MDA ignores the realities in which people suffering from NTDs live their lives. It reveals, too, the failures in the delivery strategy of MDA in Morogoro, in which the programme failed to engage in any meaningful way with the local population, resulting in widespread apprehension and rejection of treatment. And, finally, when there were very real problems with the programme that could have been addressed in an open and honest debate, these were swept under the carpet, and blamed on local agitators and heralded as a one-off, exceptional incident. It is argued here, that for treatment of NTDs to be successful it is not enough for programmes to focus on economic and biomedical aspects of treatment alone. It is imperative to consider the local social, biological, ecological, historical, economic and political contexts in which these programmes are taking place and in which the intended recipients of treatment live their lives. 
What is not called into question here is the need for treatment. It is estimated that globally 249 million people are infected with schistosomiasis, $90 \%$ of whom are located in sub-Saharan Africa, and that more than 200,000 deaths per year arise from this disease (WHO, 2012a, 2014). While both intestinal schistosomiasis ( $S$. mansoni) and urinary schistosomiasis (S. haematobium) are endemic in Tanzania (Lwambo, 1988) it is the latter that is most prevalent in Morogoro region. The World Health Organization estimates that approximately two billion people are infected with soil-transmitted helminths globally and are also endemic throughout Tanzania (Lwambo et al., 1999; WHO, 2014).

Schistosomiasis and soil-transmitted helminths are both diseases of poverty; they are prevalent in places where there is poor sanitation and limited access to clean water. Those most at risk of infection are children, who bathe, play and fetch water in these water bodies; women who perform household chores such as washing clothes and utensils; and fisherfolk. The morbidity associated with schistosomiasis and soiltransmitted helminths is well documented in the biomedical literature (see, for example, Berquist, 2002; King et al., 2005; Molyneux et al., 2005; Hotez et al., 2005, 2009; Gryseels et al., 2006; Brown, 2011; Chen et al., 2012). Schistosomosa heamatobium infection involves pathological changes to the renal and reproductive organs (Blum et al., 1998; Hatz, 2001; Gryseels et al., 2006). Both schistosomiasis and soil-transmitted helminths - particularly hookworm - can result in chronic iron deficiency anaemia due to blood loss (Lwambo et al., 1999; Hotez et al., 2005).

Established in 2005, the National Schistosomiasis and Soil Transmitted Helminth Control Programme (NSSTHCP) seeks to control the morbidity and mortality associated with schistosomiasis and soil-transmitted helminths by annual MDA with the anthelmintic drugs albendazole and praziquantel to school-aged children in endemic areas throughout Tanzania. While treatment had been undertaken in other regions in the years prior to fieldwork, 2008 was the first time mass drug administration of school-aged children was delivered in Morogoro region.

Prior to the NSSTHCP in Tanzania, treatment of schistosomiasis and soiltransmitted helminths was undertaken periodically by various organizations, and treatment of school-age children had been shown to be effective in reducing the prevalence of infection (Savioli et al., 1989; Hatz et al., 1998; Magnussen et al., 2001). A survey carried out after the first round of treatment in Tanga, northern coastal Tanzania, in the 1990s reported that while responses within the community were generally positive, parents expressed concern about the lack of communication concerning treatment as not all schools organized a meeting prior to treatment to explain the programme. Teachers reportedly said that while they were happy to administer the drugs, it considerably increased their already heavy workload with little financial incentive (Brooker et al., 2001). Furthermore, they stated that they had encountered some difficulties, such as dealing with children when they suffered side-effects and with parents who had not given consent for their children to be treated (ibid.). A decade later, similar difficulties emerged during MDA to school-aged children in Morogoro region.

\section{Methods}

This article is based on eleven months of multi-sited ethnographic research undertaken on four separate occasions in Morogoro region, Tanzania, between May 2007 and 
March 2010. Fieldwork took place in Doma village from June to September 2007 and August 2008. In Morogoro town, fieldwork took place between September and November 2008, November and December 2009 and February and April 2010. Research was undertaken throughout the town, particularly around numerous primary schools and places where people sought healing. In the latter stages of fieldwork, research focused primarily on an area known as Chamwino 'squatter' area.

The research discussed in this article was part of a doctoral dissertation (Hastings, 2013) and, initially, involved assisting in the monitoring and assessment of the National Schistosomiasis and Soil-Transmitted Helminth Control Programme (NSSTHCP) in Morogoro region, Tanzania. To do so, conventional ethnographic methods were followed. I lived in Doma village and Morogoro town, attempted to learn local idioms and languages (Kiswahili and Kiluguru) and undertook long-term participant observation. Hundreds of informal conversations took place with villagers and townsfolk from different socioeconomic backgrounds, religions, ethnicities and ages including farmers, petty-traders, nurses, doctors, midwives and other health care workers, village drug distributors, teachers, local healers, local leaders such as street and village chairpersons, members of street health committees, village ward officers and government officials. These conversations took place in homestead yards, trading centres, government offices, schools, biomedical health care facilities such as village dispensaries, medical centres, hospitals, private pharmacies, drug shops and while riding on public transport, as well as in the homes and clinics of numerous local healers (waganga) including herbalists (waganga wa miti shamba), spirit mediums and 'traditional' healers (waganga wa kinyeji).

Almost two hundred semi-structured interviews were undertaken. These usually took place at informants' homesteads in Doma village and Chamwino 'squatter' area and, in 2007, a 20\% random household survey was completed in Doma village. These interviews focused on local understandings of S. haematobium infection (known locally as kichocho) and soil-transmitted helminth infection (minyoo), as well as other NTDs such as onchocerciasis (usubi) and endemic diseases such as malaria. These interviews also elicited information on informants' previous participation or rejection of other public health campaigns - particularly community-based MDA - as well as understandings of health and illness, recent illness episodes and treatment-seeking practices more generally. In Doma village, several school quizzes, including essay and drawing competitions, were conducted in both the primary and secondary schools to help elucidate children's understandings and experiences of the body and illness, including kichocho, and minyoo.

In addition, quantifiable data such as treatment figures for S. haematobium and soil-transmitted helminths were gathered from health registers at various clinic locations within the research areas. With the exception of high-level government employees, some teachers and medical staff, interviews were conducted in Kiswahili (the lingua franca of Tanzania). In Doma village, four locally recruited primary and secondary school teachers assisted with interviews, translating and transcribing. Later, in Morogoro town, I was assisted by two final-year secondary school pupils.

In the weeks immediately following the riots, research focused on observing and collaborating with local staff working on behalf of the NSSTHCP as they collected the treatment figure forms from primary schools in Morogoro town. At this juncture discussions focused on teachers' perspectives of the events that had taken place on treatment day with those who had been involved in the drug distribution. 


\section{Fieldwork sites}

\section{Morogoro region}

Morogoro region, with a population of approximately 1.75 million (2002 census, Morogoro regional office), is the second-largest region in Tanzania. It lies in the east of the country, and for administrative purposes the region is divided into five districts: Kilombero, Kilosa, Morogoro Urban (also known as Morogoro Municipal), Mvomero and Ulanga. The sites of fieldwork (Morogoro town and Doma village) are in the districts of Morogoro Municipal and Mvomero, respectively.

The indigenous people of Morogoro region belong to a number of ethnic groups of Bantu origin, including Wapogoro, Wakonde, Kakaguru, Wasagara, Wavindonda, Wahehe, Wandingo, Wakutu and Wakwere, to name just a few. However, since the eighteenth century the Uluguru Mountains and the surrounding plains have predominately been home to people identifying themselves as Waluguru (pl.), meaning 'People of the Mountains' (Iliffe, 1979, pp. 8-9; Brain, 1980). It appears that what today constitutes 'The Luguru' began when ancestors of Bantu origin began to settle in the mountains and on the plains (Young \& Fosbooke, 1960; Pels, 1999).

The situation is similar today, particularly in Morogoro town, with migrants of disparate socioeconomic backgrounds and ethnicities arriving from all over Tanzania. The town does not therefore have one dominant ethnicity. However, those living in the so-called squatter areas such as Chamwino are predominately Waluguru, although there are also inhabitants from other areas including Wapogoro from elsewhere in Morogoro region, Makonde from Mtwara region, Nyamwezi from Tabora and Wasukuma from northern Tanzania. The majority of villagers in Doma village are Luguru, although there has been some migration into the village in recent years.

Islam dominates in the rural areas of Morogoro region, while Christians appear to form the majority in the town. One possible reason for this may be that those in rural locations converted to Islam during the time of the Arab caravans, perhaps as a means to escape capture or even to engage in trade. Conversely, in the town, Christian missionaries held the most influence (Pels, 1999). In addition, many who have arrived in the town from outside the region today are Christian. For the most part, Muslims and Christians live quite peacefully with one another in Morogoro region. Moreover, it is not uncommon to find marriages between Muslims and Christians. However, there are currently increasing concerns of tensions between Muslims and Christians on mainland Tanzania, including Morogoro region (see De Mey, 1997; Brennan, 2006; Mesaki, 2011).

\section{Morogoro town}

Nestled at the foot of the north-west slopes of the magnificent Uluguru Mountains, Morogoro town is situated approximately halfway between the commercial coastal city of Dar es Salaam, $195 \mathrm{~km}$ to the east, and the administrative capital Dodoma $253 \mathrm{~km}$ to the west. The town is governed by the Municipal Council and, for administrative purposes, is divided into nineteen sub-sections called wards (kata). These are then divided further into areas, and again, into smaller parcels called streets (mitaa). Each ward has a government-appointed Ward Executive Officer (WEO) (Afisa Mtendaji Wa Kata) 
and each street a Street Executive Officer (Afisa Mtendaji Wa Mtaa) and a locally elected Street Chairperson (Mwenyekiiti Mitaa).

Today, Morogoro town is one of the fastest growing urban centres in Tanzania. It is a sprawling settlement, with almost 300,000 inhabitants and 27,500 domestic dwellings (2002 census). The town serves as the headquarters of the region, and is the seat of regional government and the municipal and district councils. It is a bustling and ever-expanding cosmopolitan town and the Municipal Council admit that they are struggling to meet the demand for basic services such as clean water and sewerage, health care provision and school books. UN-HABITAT estimates that there are fifty unplanned, un-serviced settlements in the town. They also estimate that $65 \%$ of the town's population live in these areas, characterized by no or limited services such as clean water and sewerage systems (UN-HABITAT, 2009). These areas house people of various socioeconomic backgrounds, with those on the outskirts of the town (which have the poorest quality housing and the least infrastructure) being referred to locally as 'squatter areas' (eneo la waingiliaji ardhi/wavamiaji wa nyuma), as people do not hold deeds to the land (hati miliki) or building permits (kibali cha kujenga). These areas are home to people occupying the lowest socioeconomic status in the town.

\section{Chamwino 'squatter' area}

Chamwino area is located in the large ward of Mazimbu (population 52,656). In total, Mazimbu ward contains 32 streets and between five and six thousand households. Fourteen streets form an area called Chamwino, a so-called 'squatter area'. While the ward contains 'luxury' houses that are clearly located at one extreme of the economic spectrum, the crumbling and inadequate structures in the squatter area of Chamwino on the outskirts of town are at the other. The infrastructure here is poor and even nonexistent in several places. There are only a few public water taps (maji ya jamii ya bomba) and many of the latrines are old and disintegrating.

Unemployment is high in the squatter areas and it is frequently said (by those that do not live there) that these places are full of rapists (wabakaji), thieves (wezi), murderers (wauaji) and prostitutes (malaya kahaba). Drugs - usually marijuana (bangi) - are also said to be a big problem. Townsfolk who lived elsewhere would not wish to venture into such places after dark. These areas are not only considered lawless, but people suspect that witchcraft (uchawi) is at work in such places.

Most people living in Chamwino are engaged in some form of agricultural work but do not have a source of regular waged employment. Wherever possible - when they have the money - people supplement their agricultural work with 'petty trade'. This usually involves selling anything that can be bought and sold on for a small profit.

There are five primary schools in Chamwino area. Teachers reported poor attendance and complained that parents kept their children out of school as they did not appreciate the value of education. Indeed, it was common to find school-aged children at home when visiting homesteads either carrying out chores or engaged in trade on behalf of their households. The majority of parents and guardians interviewed said they would like their children to go to primary school more often, but frequently needed their help at home. In addition, although primary school is free, they frequently struggled to pay for exercise books, pencils and uniforms. 


\section{Doma village}

Doma village (population 3500) is located on the plains, approximately $80 \mathrm{~km}$ south of Morogoro town bordering Mikumi National Park and adjacent to the Dar es Salaam-Zambia highway. The village extends along a dirt road that turns off the main road and continues for several kilometres up into the hills. The village is comprised of six sub-villages: Doma Stand, Doma Kilosa, Doma Stoo, Mtakinini, Songa and Ngwambe.

There is a large primary school located in Songa sub-village. Between 570 and 600 children are registered, and the headmaster reported good attendance. While the majority of adult informants had not completed primary school they were keen that their own children should do so. Subsistence farming forms the basis of economic livelihood in Doma village and daily life revolves around manual agricultural work in the fields (shamba), tomatoes being the principal cash crop. Maize and cassava are grown for local sustenance, and to a lesser extent pumpkins and sweet potatoes. Other sources of income include shop-keeping, tailoring, basket-weaving and carpentry.

Villagers in Doma are predominately Muslim and there are several mosques at which most men attend Friday prayers and boys are taught the Qur'an. Few people practise Christianity - usually only those who have come to Doma to teach in the schools or to work in the dispensary - and there was no church at the time of fieldwork.

Although the environments of Doma and Chamwino are quite different, one being a rural village and one an urban 'slum', the people who live in these places shared similar anxieties over their (in)ability to feed their families, educate their children and care for the sick. Thus, life in Doma village and Chamwino 'squatter' area can be characterized as one of economic hardship and uncertainty.

\section{Rumours and riots: treatment day}

On a late August morning in 2008, Morogoro townsfolk began to hear alarming reports of children dying after swallowing drugs given to them by their teachers in primary schools. Parents and guardians rushed to the schools to find their children. An announcer on a local radio station informed listeners that children (at least four) had died after taking the drugs to treat kichocho (S. haematobium infection) and minyoo (intestinal worms) and advised parents to take their children to the hospital immediately, even if they were not experiencing any reactions, to ensure they had not been adversely affected by the drugs. When pupils heard of the 'fatalities' many of them became visibly distressed, fearing they too might die. Numerous pupils who had already swallowed the drugs reported feeling unwell; their complaints included nausea (kichefuchefu), stomach ache (tumbo kuumwa), headache (kichwa kuumwa) and dizziness (kizunguzungu). Some pupils, predominantly girls, began to faint (kuzimika).

A young mother, living in Morogoro town with two primary-school-aged children, relates her experience of that day:

We heard that six children died there [in one of the primary schools] after taking this medicine and we ran to the school to prevent our children from swallowing also. When we arrived there were many parents; some of them were arguing and fighting with the teachers and even parents began to fight each other. My daughter had swallowed the medicine and 
was fainting and suffering stomach ache (tumbo kuumwa); she was very sick (aliumwa sana). We took her to the hospital to be cured.

Similarly, a father of six from Chamwino area said:

We heard that four children in one school died after being injected (kupinga sindano) and the teachers didn't know what to do, they are not trained in this matter. Children were being rushed to the hospital. Parents had to take their sick children to the hospital...it was full of dying children; many children died here (watoto wengi walikufa hapa). More than twenty students died.

In some schools the situation quickly turned violent as parents and guardians argued with teachers who had been administering drugs. In one primary school in Chamwino a classroom wall was pulled down, school property was destroyed, the national flag removed, rocks were thrown at the teachers and one was severely beaten; one informant recounted how she saw a female teacher being beaten on the head 'like a coconut' (alipigwa kichwani kama nazi).

Other schools in the town suffered similar disturbances and teachers were physically assaulted or had rocks and stones thrown at them. The list of injuries suffered by teachers included a broken arm, a broken finger and a serious head injury. In one school a health worker had the drugs stuffed down her throat causing her to choke and vomit and in another, teachers barricaded themselves into the headmaster's office and called the police. The Field Force Unit (riot police) was mobilized and dispersed angry crowds at a number of schools using tear gas. Approximately thirty protesters were taken into police custody. The Ministry of Health and Social Welfare officially suspended the programme in Morogoro region and throughout mainland Tanzania the same day.

In all, 356 children were taken to Morogoro Regional Hospital for treatment, while many others attended health centres and dispensaries throughout the town. In Morogoro Regional Hospital ten pupils were given milk or oral rehydration therapy to drink and at least one received intravenous rehydration therapy. All the children except one (who had fallen off her bicycle on the way to the hospital) were discharged on the same day, the majority within hours. However, around this time, a child who had been in the hospital for some days, and had not received any treatment from the NSSTHCP, died due to malaria. Despite a doctor's reassurance to parents that this was the cause, many parents attributed this death to the drugs.

\section{An eyewitness account: mass drug administration in Doma village}

While these events were unfolding in Morogoro town, I was monitoring the distribution of drugs to pupils at the primary school in Doma village. Here, the headmaster called one class forward at a time and the children duly lined up with their water cups ready while the awaiting pupils giggled nervously. As each child came forward a teacher measured the child's height on a paper height chart (a praziquantel dose pole), which was attached to the wall, while another teacher recorded this into a treatment register and the headmaster administered the medicine. After each child swallowed the medicine the headmaster instructed the child to open his or her mouth so he could ensure all the pills had been swallowed. 
Most children widened their eyes or pulled a face when they saw how large the (praziquantel) tablets were and how many they were expected to swallow (usually between two and four pills); they often pulled a face upon swallowing the medicine complaining that the drugs were bitter (ni chungu). The atmosphere was reasonably relaxed and good humoured as the children's comic gestures and complaints were laughingly received by pupils still awaiting treatment and teachers alike. A few children complained of stomach ache (tumbo kuumwa) after swallowing the pills and were instructed to sit quietly or lie down in one of the empty classrooms. At one point there were around six pupils sitting in the classroom with their heads laid on the desk but usually there were three or four pupils at any one time.

For a couple of hours things progressed in much the same way until mid-morning, when the father of one of the pupils arrived. He was agitated and shouting and looked angry as he tried to locate his daughter. He informed us that four children had died in Morogoro town after swallowing the medicine and he instructed the children present not to take it. Upon hearing this pupils ran away from the drug distribution point. As the headmaster led the man to his office I contacted a doctor working on the programme who was visiting Morogoro town.

I was told rumours of child fatalities had spread before treatment had even begun and that no children had died. I told him of the events unfolding in the village and he said I should keep in touch. As I hung up I noticed a group of five or six schoolgirls lying on the ground clutching their stomachs and wailing, seemingly fearing they too were about to die. As I looked up I realized a large crowd had gathered, and more people were arriving. Some teachers and the village chairman said I should hide as they feared for my safety. 'Can you run?' asked one.

Four of us ran to the headmaster's house nearby where two of the teachers locked me and a health care worker from the local dispensary into the house from behind. We waited, with no way out, anxiously listening to the crowd outside hoping they would not detect us. After almost an hour two large blows to the front door sent it crashing open revealing two armed police officers; 'Come!' said one, in English. Outside the crowd had grown considerably in size since I had taken to my hiding place and there were now approximately two hundred people. The villagers stared and some shouted as I was led to a waiting car. I heard the words sumu (poison) and mzungu (foreigner/white person) being shouted by some in the crowd. Sitting in the back of the car I was flanked on one side by a police officer - still armed - and the village chairman on the other. The other police officer sat next to the driver. Nobody spoke as we crawled at an alarmingly slow pace to the police station which was located at the side of the highway close to my lodgings. I did not know where the health worker had gone but later learnt she was safe, if rather shaken herself. Once at the police station I was advised to leave Doma immediately as the village government and police feared for my safety, many villagers believing I had personally brought bad medicine (dawa mbaya) into the village to poison their children (mwekaji wa sumu mzungu). I left the village and never returned.

\section{The official explanation}

In the following days, government officials and police officers - led by the local Criminal Investigation Department (CID) - reported that the 'rumours' had been started 
by, what they called, 'anti-government agents' in the region, who sought to embarrass the government by ensuring the treatment programme failed. Opposition party activists belonging to the Tanzanian Labour Party (TLP) were accused of planning the disruption with the assistance of a retired health education officer who was deemed responsible for starting the malicious text messages. Local unemployed youth, known pejoratively as 'street boys', were said to have been paid small sums to ride around on their bicycles perpetuating the rumours. Government officials, health workers and those working with the NSSTHCP readily concurred and blamed the failure of the exercise on 'anti-government hooligans and agitators', not questioning how unhesitatingly these stories had been accepted by the majority of those who had heard them.

The lack of adequate food prior to the consumption of the tablets was blamed for the adverse effects experienced by some of the children, although health care workers and teachers also noted that most of the children had been seemingly healthy after receiving treatment until they heard rumours of child fatalities, which, they said, caused pupils to panic (hofu kubwa) and feel faint (kuzimika).

While these explanations are not altogether inaccurate, they only provide a partial and official perspective of events, in which the rumours, those who spread them, and acted - sometimes violently - because of them, are held accountable for the failure in treatment. By apportioning blame in this manner, any failings in the way the programme operated is ignored. So too is any consideration of the social and political context in which the NSSTHCP operated.

\section{Alternative explanations}

Despite the official explanation of events, many people continued to suspect that children had died or been harmed as a result of treatment. New theories emerged daily - both in the town and in national newspapers (for example, Habari Leo, 30th August 2008; Tanzania Daima, 30th August 2008; Mtanzania, 30th August 2008; Tanzania, 1st September 2008; Nipashe, 1st \& 2nd September 2008; Majira, 2nd September 2008), which continued to challenge the official version of events. In the ensuing days and weeks there was a pervasive feeling among many townsfolk that something was terribly wrong with this treatment programme. How people understood and explained these events varied, and were largely dependent upon a person's socioeconomic status. Explanations ranged from the notion that while the programme was perhaps well-intentioned it was incompetently run, to theories that the NSSTHCP had used expired, counterfeit or experimental drugs due to government corruption, or that the entire programme had been a clandestine attempt, orchestrated by Western governments, to sterilize African children. These theories emerged in response to the programme's delivery strategies.

\section{Dilemmas in delivery strategy in Morogoro town}

Many parents and guardians in Morogoro town were adamant that the first they knew of the drug distribution was when they heard of children dying because of it. The dearth of information made available to parents and guardians beforehand not only caused confusion and chaos surrounding drug administration on treatment day, but also raise 
serious ethical concerns surrounding the issue of consent. Why was it deemed permissible to give drugs to African children without their parent or guardian's consent when this would be intolerable in the countries where drugs such as these are manufactured - in Europe and the United States? As one grandmother complained:

I was not informed [of the mass drug administration]. There must be education if our children are to be given drugs. The parents should go with the children to give approval. It is not correct that only the teachers had information, they are not medical people.

Parents and guardians received inadequate or no information for several reasons. First, information regarding the deworming exercise (i.e. both schistosomal and helminth infections) circumvented the usual channels of communication. Normally, any information for public consumption (such as health education) passes 'down' the hierarchical levels of government from central to municipal/district to ward and finally, to street level. However, after holding meetings at municipal level, schools were instead responsible for informing the wider 'communities', including pupils, parents, guardians and street-level leaders. Unfortunately, the majority of Street Chairpersons (Mwenerkiti Mitaa) and other street-level organizations such as Street Health Committees (Kamati Ya Afya Ya Mtaa) were not informed of the scheduled MDA and could not therefore be instrumental in informing those in the 'community' (jamii) as they usually would have done. As one Street Chairperson recollects:

They didn't inform us [Street Chairpersons] so they told teachers only. It is better to inform the Street Chairmen as we live with the community...We know how to tell them [people] if there's a problem we know how to solve it with the people. The information was not good. (Street Chairperson, Chamwino area)

Second, teachers were given insufficient time to adequately inform parents of the scheduled treatment:

We needed longer to sensitize the community - up to one month...It was too sensitive and the time was too short... (Head teacher, primary school, Morogoro town)

We [teachers] are being blamed for the problems but we did not have good enough time to prepare the community about this programme. (Health teacher, primary school, Morogoro town)

In most cases, meetings were held at the schools one or two days before the scheduled drug administration but attendance was poor. Even when parents were aware of these meetings, many complained they had been given insufficient notice to attend due to conflicting commitments, particularly agricultural duties.

Third, the health education that was provided during these meetings appears to have been minimal. Teachers informed people that treatment would take place, but not necessarily the rationale for the targeted MDA of all primary school age children or the method in which the drug dose would be calculated (by height rather than weight). Of course, it is impossible to determine exactly what was discussed at each of these meetings and from parents' comments it seems as though some schools provided more information than others. However, the principal message given by teachers (both at meetings and letters sent home) seems to have been the necessity for children to eat 
beforehand, so they might avoid experiencing stomach ache after ingesting the drug (praziquantel) to treat kichocho. This also involved telling parents that the Municipal Council had provided funds for the provision of porridge at school although it was still advisable for children to eat at home before attending school. While this may have been sensible advice it was unrealistic: most children in Morogoro town (especially those from lower socioeconomic households like those in Chamwino) usually eat one meal a day in the early evening with the rest of their household. Indeed, the Municipal Council's provision of funds for porridge was a response to this reality, but it was often inadequate.

With little other information available or a forum in which parents could have voiced concerns or asked questions (and received honest and sensible answers) the importance placed on the need for food became the principal message, when one was heard at all. The apparent need for food suggested that the drugs (particularly praziquantel) were very strong (dawa kali) and fuelled speculation that the fatalities, 'side-effects' and other untoward physical manifestations experienced by the children were because the drugs were too powerful for the bodies of African children.

\section{Questioning mass drug administration: divergent understandings}

Schistosomiasis is translated in Kiswahili as kichocho and soil-transmitted helminths (worms) as minyoo. Indeed this is what locals call them. However, by comparing people's understandings of kichocho and minyoo in Morogoro town and Doma village with those working to control these NTDs at a global level it becomes clear that while there are certainly points of overlap, there are also significant areas where they diverge. This is particularly pertinent when considering perceptions of whether or not these parasitic diseases are a serious health problem. In common with Geissler's (1998) research on children's perceptions of worms among the Luo in Kenya, people in Doma and Morogoro town were resigned to the idea that kichocho and minyoo were unavoidable nuisances and, as such, 'just part of life' and 'normal' (ya kawaida). In contrast to the perspectives of policymakers, kichocho and minyoo were not considered to be major health problems; after all, no one had seen or heard of anyone dying from them. Indeed, many townsfolk were bewildered by this public health intervention that sought to provide free drugs to all primary-school-aged children for seemingly minor ailments, especially when children were dying from 'serious' diseases like malaria and cholera.

While there was generally a reasonable biomedical understanding of the aetiology, transmission and even treatment of these two diseases, most misunderstandings occurred around the rationale and method for the treatment of kichocho. Treatment for intestinal worms (minyoo) was usually welcomed as most parents felt their children were troubled by worms. Furthermore, in contrast to the drug praziquantel (which is used to treat schistosomiasis), people in Morogoro were familiar with the drug albendazole, which is used to treat minyoo. Not only had it been administered in other public health campaigns before (unlike praziquantel), but local pharmacies and drug shops frequently reported selling it. Moreover, only one albendazole tablet was required for each child whereas the praziquantel dose usually required multiple tablets (between one and four, depending on the child's height). 
Many of the parents' and guardians' reservations regarding their children's need for treatment for kichocho (usually retrospectively) were grounded in previous experiences of biomedical care, often in relation to seeking treatment for malaria at local dispensaries, health centres and hospitals. After the MDA, numerous questions were raised about the programme. These include the following:

\section{Why did they not test the children first?}

Locally, it was overwhelmingly thought that kichocho was always symptomatic: recognizable by blood in the urine (mkojo wa damu). Indeed, it was thought impossible to be infected with kichocho and not know it. Therefore, many parents and guardians could not comprehend why their children were being treated when they did not have bloody urine and were not therefore infected. Haematuria (blood in the urine) is a clear indication of $S$. haematobium infection. In endemic areas of sub-Saharan Africa, this sign is regarded as the 'red flag' of infection in children (Gryseels et al., 2006, p. 1108). However, haematuria (or more correctly, gross or macrohaematuria), which is visible to the naked eye, may disappear with time even though infection, and microhaematuria (which is only visible under a microscope) remain, leading people to conclude, incorrectly, that they are not infected. Microscopic urinalysis is therefore the 'gold standard' method of detecting infection.

Most people in Morogoro town were familiar with the need for blood tests to confirm a diagnosis of malaria, or a stool test to diagnose intestinal worms (minyoo). Why then, they asked, were the children to be given drugs to treat kichocho when they had not been tested (by observation of urine microscopically or otherwise) first? Moreover, it was overwhelmingly considered inappropriate (with the exception of infants) to take medicine unless one was sick. This practice was frequently supported by staff in the medical facilities, who discouraged the habit (at least in adults) of taking medicine, particularly for malaria, without being tested first. The absence of screening pre-treatment led many people to question the MDA for the treatment of kichocho and they frequently provided alternative explanations for the 'true' rationale for treatment, as comments such as these illustrate:

These drugs that were brought here, they are to stop them [the children] from having their
own families. Why else were they to be given to all [children] whether they were suffering
from kichocho or not? They would have tested...if it was for kichocho. (Grandmother,
Chamwino)

The nurses here [at the dispensary] tell us to check our blood before taking drugs for malaria so why did our children take this medicine when they did not check them for this [kichocho)? ... It is because this was not to treat kichocho... (Mother, Chamwino)

Those responsible for 'sensitizing' the local population, teachers, medical staff and other government officials, did not address such concerns. Indeed, the majority of teachers interviewed were unable to explain why all the children were to be treated without prior urinalysis. Usually they would just state it was because kichocho was a 'big problem' and be unable to elaborate further. 
Why give the children this medicine when they will become infected again?

Another perplexing issue for many parents and guardians in Morogoro town, and one which was frequently voiced in the aftermath of the attempted distribution of drugs, was the seeming futility of treating children when they would go back in the infested water, perhaps even on the same day, and be re-infected:

They say this drug is to treat kichocho but it cannot work. No! The children here [Chamwino] will swim in the ponds again...Every day! Every day! You understand?...So they will have kichocho even if they take this medicine in the school. If they [the government] wanted to wipe out kichocho why don't they direct their efforts and put something in the water to really kill it [kichocho]? (Father, Chamwino)

Children take the drugs in the morning and go swimming in the afternoon so what is the point? It cannot cure kichocho. (Father, Morogoro town)

The lack of education concerning the rationale for MDA to treat kichocho when children may easily be infected again, and the apparent inability of teachers to answer pertinent questions based on parents and guardians' reasonable biomedical understandings meant that the rationale for treating the children for kichocho was, for many people, puzzling and ambiguous. This in turn led to suspicion surrounding the treatment campaign as people questioned whether the drugs had really been given to treat kichocho or for something else entirely.

\section{Why did teachers administer the drugs and not nurses?}

Although health care workers had been present at many of the schools they had not been especially visible and parents were often unaware that they had even been involved in the administration of the drugs. Furthermore, several teachers complained that they had not been supervised or given support from the health workers in the way they had expected. The choice of teachers to administer the drugs caused great concern in the town: why, people asked, were the drugs given to the children by teachers rather than nurses, and why in schools and not in hospitals? 'Teachers for education and nurses for health care' was a common adage. Such concerns appeared justified, when, as many thought, the teachers - lacking in the requisite medical skills - administered incorrect dosages and were then also incapable of assisting the 'sick' and 'dying' children.

The correct dose of praziquantel for the treatment of schistosomiasis is $40 \mathrm{mg} / \mathrm{kg}$, and, as each tablet contains $600 \mathrm{mg}$, the numbers of tablets that need to be swallowed vary between individuals. Although the dose here is calculated according to weight, following World Health Organization (WHO) guidelines, during mass drug administrations in Tanzania (and elsewhere) the dose is measured by height, using a 'praziquantel dose pole'. The WHO guidelines state that dose poles are preferred over weighing people for several very good reasons, including: they are cheaper; do not have parts that can break; are simple and quick to use; do not involve calculations; are accurate and safe to use as children's height and body weight generally correlate, and where they do not the dose received is still of an acceptable level (Hall et al., 1999; WHO, 2006). It is a pity this information was not shared with the townsfolk of Morogoro, who were only familiar with weight being used to establish a correct dose in health care facilities. 
In the days following MDA, a pervasive suspicion was palpable in the town that the teachers had 'overdosed' the children due to their inexperience and incompetence by measuring the children's height to establish the dose rather than weighing them. People pointed out that while a child might be tall he or she could also be slim - as was usually the case - or even underweight or malnourished, resulting in the child getting too many pills for their body weight:

The children who were sick, they were tall but not much weight and the drugs were too many for them. The teachers should not have done it like this, they should have weighed all the children but they are not nurses they do not know the correct ways. (Father, Morogoro town)

Pupils, too, feared they had been given too many drugs by their teachers, as was reported in one of the national newspapers:

Some of the students talking to Majira at another time said they were given the medicine according to their height so some were given two, three, and up to five tablets and this situation convinced them that this was the root of the side effects. (Majira newspaper, Saturday 30th August 2008)

Arguments between parents and teachers over this issue of dosage were common, as the following accounts from school teachers illustrate:

No pupils received the drugs [here], I failed. The parents came...They said 'you want to kill my only son...' They said 'Why do you give without measuring weight? Height is not a proper measurement.' So that is a problem too, as they say in the rumours that there is a problem not weighing the children. (Head teacher, primary school, Morogoro town)

One parent hit out at our health teacher saying she did not know what she was doing and that she was giving the children too many drugs ... We attempted to explain to him that this was the correct way but he would not believe us. He said we were responsible for killing the children, but no pupils died here. (Assistant head teacher, primary school, Chamwino)

Arguments such as these highlight the lack of confidence people had in the teachers' ability to administer the drugs 'correctly'. This was most acutely felt in Chamwino 'squatter' area where there had been long-term animosity between parents and teachers and where the most violent rioting occurred on treatment day. The wisdom of using teachers to educate parents in places where antagonistic relationships were already known to exist (by health care workers and teachers) is questionable at best. On the one hand, teachers and health workers said it was difficult to educate parents in these areas and appeared resigned to facing opposition from parents. On the other hand, parents said the teachers didn't tell them anything. Whatever the 'truth', it is clear that these were not the ideal environments in which to have an open and honest forum concerning the deworming programme in which parents could express their anxieties to teachers. Such a 'one size fits all' approach, whereby, in this case, school teachers were considered the best people for the task of distributing medicine to children regardless of the local specificities, appears to defy all logic, and was in part responsible for the failure of the programme. 
Astonishingly, the understanding that measuring the children's height to determine the dosage of praziquantel had been a mistake was seemingly 'confirmed' by the acting director of Tanzania Food and Drug Administration (TFDA), Hiiti Sillo, when, during his visit to Morogoro in the days following drug administration, he reportedly told a journalist, '...[T] here were a number of deficiencies in how the drug was given, such as giving children the vaccine without weighing them...' (Mwananchi newspaper, $1^{\text {st }}$ September 2008).

In the aftermath of the riots, teachers were very clear in voicing their opinions to programme staff visiting the schools:

Teachers should not continue with this exercise. I am not a doctor! Some teachers have asked the government to omit treatment in schools and use the sectors responsible like the Ministry of Health and health workers. Next time we will not obey in this exercise. (Head teacher, Morogoro town)

Please do not give in schools, we are not capable - they [the pupils] need a nurse or doctor at the health centre. We will not do it again; the parents will have to take the children to the medical centre or hospital. The teachers will not be willing to take the responsibility again as that day six hundred parents came asking 'what is this sister?' and we were not able to respond. (Teacher, primary school, Morogoro town)

Many teachers felt, in retrospect, they had not been the correct people for the job. Having been abused both verbally and physically they now felt they were being used as a scapegoat for the failings of the programme and numerous teachers complained that they would be unwilling to participate in future programmes.

\section{Poisoned children: new rumours for new times?}

Why did they poison our children? These drugs are to destroy the reproductive system (mfumo wa uzuzi) - it is for family planning (uzazi wa mpango). These children [the ones who swallowed the drugs] they will not have any children or perhaps only one (hawatapata watoto au labda mmoja tu). (Mother of school girl, Morogoro town)

The word 'rumour' is a loaded one; its use commonly conjures up notions of dubious stories and conspiracy theories with questionable validity in the popular imagination. Within this official perspective, rumour is understood as 'unreliable oral information' (White, 2000, p. 56) that officials '... have not engendered, shaped or controlled' (ibid., p. 210). Indeed, this was certainly the official view of malicious stories about child fatalities and theories of faulty drugs, overdoses, drugs trials and covert sterilization campaigns.

In the local context, poison (sumu) is also a loaded word and in the days and weeks after the riots, people frequently asked (often rhetorically) of the NSSTHCP, 'Why did they poison our children?' Drawing from the idiom of witchcraft, poisoning can involve anything that is detrimental to the person or household that has been bewitched (uchawi). With regards to health, this can include any type of physical illness - minor, major, fatal, chronic or acute - but frequently involves harm to a person's reproductive capacity. Therefore, when people asked why the children had been poisoned, although they could be alluding to a number of things, such as the transitory physiological effects 
experienced by the children (dizziness, headache and stomach ache) they were nearly always alluding to their suspicion that the medicine distributed had been an anti-fertility drug (dawa ya kuzuia kuzaalmimba).

By masquerading as medicine to treat kichocho (and minyoo) it was widely believed the anti-fertility drugs could be delivered to as many school children as possible. That the NSSTHCP had been a covert sterilization exercise explained many of the doubts that had been expressed by parents and guardians (either before or after MDA). For example, why the drugs had been administered in schools rather than hospitals, by teachers rather than health care workers, (seemingly) irrespective of whether or not the children were infected. Those who expressed ideas such as these nearly always belonged to the poorest socioeconomic groups in the town. Although, very occasionally, even well-educated Tanzanians, as well as European and American ex-pats and missionaries, also expressed an opinion that they would not be surprised if it was later discovered anti-fertility drugs had been used. Theories of covert sterilization were also the most tenacious; over two years later people throughout Morogoro town were still referring to the deworming programme as the one that tried to sterilize the children.

Explanations such as these illuminate local peoples' anxieties that the Tanzanian government, as well as other governments in different countries across sub-Saharan Africa, are trying to reduce their populations as a result of coercion from the international community, as these two examples from semi-structured interviews with a teacher and two mothers (respectively) illustrate:

JH: Why do people think the drugs are to sterilize the children?

Health teacher (HT): We are always being told that Africans have too many children and we need to reduce our families.

$\mathrm{JH}$ : Who is telling you that?

HT: It is those in the developed world who say we Africans (Waafrika) are too many.

JH: Why do you think people are saying the drugs were brought here to sterilize the children?

Mother 1: Because the drugs prevent reproduction.

Mother 2: It is to depopulate Africa; they say there are too many Africans...

JH: Who says there are too many Africans?

Mother 2: Wazungu (white people) [laughs]

Mother 1: Central government...

Within the social sciences, rumours are conventionally understood as counternarratives of marginalized groups in subordinate social relationships. Indeed, among 
anthropologists, as Butt notes, '... the term rumour has been widely used to describe collective imaginaries reacting to experiences of inequality' (Butt, 2005, p. 414). Writing on the emergence of vampire rumours in colonial East Africa, the historian Luise White (White, 1995, 2000) contended that these rumours were a way of imagining new relationships at a particular (colonial) moment in time. White proposed that rumours such as these can be used as a diagnostic tool, in which to reveal local anxieties surrounding national and global projects (White, 1995). Is it possible to view rumours of poisoned (sterilized) children in Morogoro town the same way? Various authors have shown that rumours have emerged in response to the experiences and anxieties surrounding (to name a few) colonial labour practices (Pels, 1992), colonial biomedicine (White, 2000) and local inequities of wealth (Weiss, 1998). Similarly, Sanders (2001) argued convincingly that organ-stealing rumours emerged in response to the hardships borne out of structural adjustment policies in Tanzania.

What, then, can poisoning rumours tell us about the daily realities and current anxieties of people living in Doma village and Morogoro town? Why would people suspect the NSSTHCP of nefarious practices, such as using experimental drugs on their children or running a covert sterilization campaign? Why would people suspect their government and Western donor organizations of being involved in such conspiracies? Not surprisingly, there is no single answer to these questions. Rather, several factors coalesced and contributed to local explanations (some would say rumours) surrounding this biomedical intervention. Firstly, is the way in which the programme itself operated; with inadequate communication being provided about the rationale for treatment and other delivery strategies. Second, and exacerbated by the first, was the disjuncture between local and global health perspectives of kichocho and S. haematobium infection. Understanding that a lack of information can potentially lead to rumour is a conventional one within public health, and organizations such as UNICEF routinely implement methods to explicitly confront rumours surrounding immunization programmes in an effort to dispel them (Kaler, 2009).

Biomedical interventions like these do not operate in a vacuum and as anthropologists and other social scientists have commented (Feldman-Savelsberg et al., 2000; Yahya, 2007: Kaler, 2009), it is always necessary to examine the particular social, political and historical context in which rumours arise. In Morogoro town and Doma village, there was a ubiquitous public health campaign aimed at family planning coupled with a common development discourse concerning the over-population of Africa. In all government health care facilities visited there was, without exception, at least one poster on the wall encouraging the use of contraception. With the population of Tanzania projected to reach 65 million by 2025 and with half of the current population under the age of fifteen years, there has been renewed effort by the Ministry of Health and Social Welfare, supported by international donors (such as the United Nations Population Fund, the World Health Organization and the World Bank), to increase modern contraceptive prevalence rate from the current $28 \%$ to $60 \%$ by 2015 (National Family Planning Costed Implementation Program, 2010-2015).

Sterility rumours such as these, which emerge during public health campaigns, reveal widespread anxieties relating to perceived threats to reproduction in sub-Saharan Africa. As such, these rumours allow for local discussion, negotiation and resistance (Scott, 1985 ) in the face of hegemonic global development, including global health interventions 
such as this one, in which decisions are, as Yahya notes, '...made in environments far removed from the local realities of targeted societies, resulting in an awkward clash between grand global objectives and local priorities, practicalities and peculiarities (Yahya, 2007, p. 203).

\section{An isolated incident?}

The findings detailed in this paper resonate with long-term anthropological research on other biomedical interventions seeking to control NTDs, such as $S$. mansoni and soiltransmitted helminths in Uganda (Parker et al., 2008; Parker \& Allen, 2011; Parker et al., 2012) and lymphatic filariasis and soil-transmitted helminths elsewhere in Tanzania (Parker \& Allen, 2013a, b). These findings echo earlier difficulties with NTD control in Tanzania (Brooker et al., 2001) and recent research in Uganda continues to detail similar findings (Muhumuza et al., 2015). While the riots in Morogoro town may be an extreme example of rejection of treatment for NTDs, research in Uganda and Tanzania concerning MDA for NTDs also identifies local resistance(s) to treatment for a number of almost identical reasons, including ineffective health education and fears of infertility, illness and even death following treatment (Parker et al., 2008; Allen \& Parker, 2011).

The sterility rumours that surrounded the NSSTHCP in Morogoro echo those occurring elsewhere in sub-Saharan Africa (see Kaler, 2009). For example, the rejection of the oral polio vaccination in northern Nigeria (Yahya, 2007; Renne, 2010) and an anti-tetanus campaign in Cameroon (Feldman-Savelsberg et al., 2000), where sterility rumours also arose and where there was widespread resistance to treatment that revealed anxieties of internationally led eugenics plots. However, even in these cases, there were also other concerns relating to the way in which the programmes administered the drugs and by whom. While recognizing that the political, economic and social context profoundly shapes the way in which mass treatment is received, this article also highlights important issues in the delivery strategies of programmes that seek to control NTDs well beyond Morogoro region and Tanzania.

However, having anthropologists 'on board' does not necessarily mean policymakers and global health experts will be interested in their findings; they are all too apt to consider anthropological research anecdotal, or to put their findings down to 'an isolated occurrence' (Allen \& Parker, 2012). In some cases, they have not only sought to dismiss or ignore uncomfortable findings, but also to silence critical voices (Parker \& Allen, 2014). In spite of the grounded evidence, based in theory, that anthropologists (and other social scientists) have provided (Yahya, 2007; Coulibaly et al., 2008; Parker et al., 2008; Cavalli et al., 2010; Parker et al., 2012), this has not translated well into use by policymakers, as they do not always appear to recognize this is valid evidence on how to (or not to) implement these programmes. This raises the question: whose knowledge counts? Surely the answer must be that knowledge(s) from both the biological and social sciences, although different, are both valid and need to be integrated (Goodman \& Leatherman, 1998; Allen \& Parker, 2012). Indeed, if the aim is to control these parasitic diseases, then it is imperative to move forward with a unified biosocial approach that takes into consideration the biological, biomedical, socio-cultural, political, ecological and historical dimensions involved in providing treatment to the world's poor. 


\section{Conclusion}

Biomedical programmes to control NTDs have the potential to go wrong, and, as illustrated here, may go wrong in a dramatic and even violent manner. Policymakers and planners working on programmes seeking to control NTDs should consider how they use the work anthropologists and other social scientists develop in the field in order to improve the likelihood of successful outcomes for the delivery of treatment to control NTDs.

The NSSTHCP in Morogoro was rejected for several reasons. Vertical 'top down' programmes such as these pass information 'down' but not 'up' (Feierman et al., 2010). This resulted in local voices not being heard, or listened to, including pertinent questions from parents and guardians concerning the rationale as well as the method of MDA. For example, it would have been helpful if parents had been told about the method of calculating the dosage by height as it could have reduced anxieties regarding the perceived potential to overdose the children. Similarly, the biomedical rationale for treatment should have been explained, focusing on the reason for providing preventive chemotherapy even when it is clear that there is a strong likelihood that children will be infected again once they enter infected water. Also, it might be worth the expense of using reagent strips to conduct urinalysis pre-treatment, if this means more children are likely to receive the drugs.

There was also inadequate notice beforehand to street-level leaders, and while higher level government employees were informed, this did not 'trickle down' to the grass-roots. This was due in part to the way the NSSTHCP circumvented the usual channels of communication between government levels and departments and the apparent rapidity with which MDA was rolled out. Ultimately, a 'one size fits all' approach ignored the local political, historical and social context. For example, the antagonism between parents and teachers in Chamwino meant that teachers were the least appropriate people to be delivering the drugs. Although this was a very localized and specific occurrence, there was still a pervasive understanding throughout the town that school teachers were not adequately qualified for such a role and it would be preferable to use health care workers. It would therefore be worth considering administering the drugs in health centres and hospitals rather than schools in future.

However, even if parents and pupils had been better informed, it does not necessarily mean that fears and rumours of covert sterilization campaigns would simply have disappeared. These are deep-rooted anxieties, embedded in historical, political and global relationships. Furthermore, the current climate of development discourse, which focuses on the over-population of countries such as Tanzania, and the need to reduce population growth if development goals are to be achieved, raises fears among marginalized groups that it is not so much the international community's aim to reduce the number of Africans living in poverty, but to reduce the number of poor Africans.

With the spotlight currently on the very real need to offer treatment for these horrible diseases and recent successes in funding, the Director General of the WHO, Margaret Chan, said at a speech in Geneva in May 2012, 'These Cinderella diseases, long ignored and underappreciated, are a rags-to-riches story' (WHO, 2012b). However, the anthropological research presented in this article has shown that the people who suffer from these diseases continue to be overlooked; they are still waiting to be invited 
to the ball. While programmes to control NTDs continue to ignore the socio-political context in which people suffering from these diseases live and suffer, they will remain neglected.

\section{Acknowledgments}

Fieldwork for this paper was undertaken in Tanzania under the auspices of the Schistosomiasis Control Initiative (SCI), Imperial College London, the National Institute for Medical Research (NIMRI), and the Tanzanian Commission for Science and Technology (COSTECH). My doctoral research was part of a wider study led by Melissa Parker and Tim Allen assessing the roll of MDA for the treatment of NTDs in sub-Saharan Africa. Fieldwork funding was provided by SCI and the School of Social Sciences, Brunel University. I am grateful to Alan Fenwick, Director of SCI, for his support during my fieldwork and also to SCI programme managers Lindsey Blair and Alice Norton. I would like to thank Melissa Parker, Tim Allen and Eric Hirsch for their guidance during this project. In Tanzania I would especially like to thank Peter Kilima as well as the late Nicholas Lwambo, Elizabeth Massi, Ursuline Nyandindi and the late Divina Masashua. It saddens me immensely that my time in Doma village ended the way it did; I would like to express my gratitude to the villagers as well as those in Morogoro town who shared their stories with me.

\section{References}

Allen, T. \& Parker, M. (2011) The 'other diseases' of the Millennium Development Goals: rhetoric and reality of free drug distribution to cure the poor's parasites. Third World Quarterly 32(1), 91-117.

Allen, T. \& Parker, M. (2012) Conflicts and compromises: experiences of doing anthropology at the interface of public policy. In Fardon, R., Harris, O., Marchand, T. H. J., Shore, C., Strang, V. \& Wilson, R. A. (eds) Sage Handbook of Social Anthropology, pp. 184-195.

Berquist, N. R. (2002) Schistosomiasis: from risk assessment to control. Trends in Parasitology 18(7), 309-314.

Blum, J., Beck, B., Strnad, I. \& Hatz, C. (1998) Vulvar lesion in urogenital schistosomiasis (S. haematobium). Zeitschrift für Geburtshilfe und Neonatologie 202(6), 255.

Brain, J. L. (1980) The Uluguru Land Usage Scheme: success and failure. Journal of Developing Areas 14(2), 175-190.

Brennan, J. R. (2006) Blood enemies: exploitation and urban citizenship in the Nationalist Political of Tanzania, 1958-75. Journal of African History 47, 389-413.

Brooker, S., Marriot, H., Hall, A., Adjei, S., Allan, E., Maier, C. et al. (2001) Community perception of school-based delivery of anthelmintics in Ghana and Tanzania. The Partnership for Child Development. Tropical Medicine and International Health 6(12), 1075-1083.

Brown, M. (2011) Schistosomiasis. Clinical Medicine 11(5), 479-482.

Butt, L. (2005) 'Lipstick Girls' and 'Fallen Women': AIDS and conspiratorial thinking in Papua, Indonesia. Cultural Anthropology 20(3), 412-442.

Cavalli, A., Bamba, S. I., Traore, N. M., Boelaert, M., Coulibaly, Y., Polman, K. et al. (2010) Interactions between global health initiatives and country health systems: the case of a neglected tropical diseases control program in Mali. PLoS Neglected Tropical Diseases 4(8), e798. doi:10.1371/journal.pntd.0000798 
Chen, W., Flynn, E. A., Shreefler, M. J. \& Blagg, N. A. (2012) Schistosomiasis. Obstetrics and Gynaecology 119(2), 472-475.

Coulibaly, Y., Cavalli, A., van Dormaei, M., Polman, K. \& Kegels, G. (2008) Programme activities: a major burden for district health systems? Tropical Medicine and International Health 13(12), $1430-1432$.

De Mey, M. (1997) Controversial issues in Christian-Muslim relations in East Africa. Exchange 3, 265-279.

Feierman, S., Kleinman, A., Stewart, K., Farmer, D. \& Das, V. (2010) Anthropology, knowledgeflows and global health. Global Public Health: An International Journal for Research, Policy and Practice 5(2), 122-128.

Feldman-Savelsberg, P., Ndonko, F. T. \& Schmidt-Ehry, B. (2000) Sterilizing vaccines or the politics of the womb: retrospective study of a rumour in Cameroon. Medical Anthropology Quarterly 14(2), 159-179.

Fenwick, A., Molyneux, D. \& Nantulya, V. (2005) Achieving the Millennium Development Goals. The Lancet 365(9464), 1029-1030.

Geissler, P. W. (1998) 'Worms are our life', part I: understandings of worms and the body among the Luo of western Kenya. Anthropology and Medicine 5(1), 63-79.

Goodman, A. H. \& Leatherman, T. L. (eds) (1998) Building a New Bicultural Synthesis: Political - Economic Perspectives on Human Biology. University of Michigan Press, Ann Arbor.

Gryseels, B., Polman, K., Clerinx, J. \& Kestens, L. (2006) Human schistosomiasis. The Lancet 368, $1106-1118$.

Hall, A., Nokes, C., Wen, S.-T., Adjei, S., Kihamia, C., Mwanri, L. et al. (1999) Alternatives to bodyweight for estimating the dose of praziquantel needed to treat schistosomiasis. Transactions of the Royal Society of Tropical Medicine and Hygiene 93, 653-658.

Hastings, J. (2013) Rumours and riots: local responses to mass drug administration for the treatment of neglected tropical diseases among school-aged children in Morogoro Region, Tanzania. PhD thesis, Brunel University, London.

Hatz, C. F. (2001) The use of ultrasound in schistosomiasis. Advances in Parasitology 48, 225.

Hatz, C. F., Vennervald, B. J., Nkulila, T., Vounatsou, P., Kombe, Y., Mayombana, C. et al. (1998) Evolution of Schistosoma haematobium-related pathology over 24 months after treatment with praziquantel among school children in southeastern Tanzania. American Journal of Tropical Medicine and Hygiene 59(5), 775-781.

Hotez, P. J., Bethony, J., Botazzi, M. E. \& Buss, P. (2005) Hookworm: the great infection of mankind. PLoS Medicine 2(3), e67.

Hotez, P. J., Fenwick, A., Savioli, L. \& Molyneux, D. H. (2009) Rescuing the bottom billion through control of neglected tropical diseases. The Lancet 373, 1570-1575.

Hotez, P. J. \& Thompson, T. G. (2009) Waging peace through neglected tropical disease control: a US foreign policy for the bottom billion. PLoS Neglected Tropical Diseases 3(1), e346.

Iliffe, J. (1979) A Modern History of Tanganyika. Cambridge University Press, Cambridge.

Kaler, A. (2009) Health interventions and the persistence of rumour: the circulation of sterility stories in African public health campaigns. Social Science \& Medicine 68, 1711-1719.

King, H., Dickman, K. \& Tisch, D. J. (2005) Reassessment of the cost of chronic helminth infection: a meta-analysis of disability related outcomes in endemic schistosomiasis. The Lancet 365, 1561-1569.

Lwambo, N. J. S. (1988) Transmission of urinary schistosomiasis in Sukumaland, Tanzania: snail infections rates and incidence of infection in school children. Journal of Helminthology 62(3), 213-217.

Lwambo, N. J. S., Siza, J. E., Brooker, S., Bundy, D. A. P. \& Guyatt, H. (1999) Patterns of concurrent hookworm infection and schistosomiasis in schoolchildren in Tanzania. Transactions of the Royal Society of Tropical Medicine and Hygiene 93, 497-502. 
Magnussen, P., Ndawi, B., Sheshe, A. K., Byskov, J., Mbwana, K. \& Christensen, N. O. (2001) The impact of a school health programme on the prevalence and morbidity of urinary schistosomiasis in Mwere Division, Pangani District, Tanzania. Transactions of the Royal Society of Tropical Medicine and Hygiene 95, 58-64.

Mesaki, S. (2011) Religion and the state in Tanzania. Cross-Cultural Communication 7(2), 249-259.

Molyneux, D. H., Hotez, P. J. \& Fenwick, A. (2005) 'Rapid impact interventions': how a policy of integrated control for Africa's neglected tropical diseases could benefit the poor. PLoS Medicine 2(11), e63-e81.

Muhumuza, S., Olsen, A., Nuwaha, F. \& Katahoire, A. (2015) Understanding low uptake of mass treatment for intestinal schistosomiasis among school children: a qualitative study in Jinja district, Uganda. Journal of Biosocial Science 47, 505-520.

National Family Planning Costed Implementation Program (2010-2015) URL: www.fhi.org/NR/ .../NatlPlanFPImplementationTZmain.pdf (accessed 1st December 2012).

Parker, M. \& Allen, T. (2011) Does mass drug administration for the integrated treatment of neglected tropical diseases really work? Assessing evidence for the control of schistosomiasis and soil-transmitted helminths in Uganda. Health Research Policy and Systems 9, 3.

Parker, M. \& Allen, T. (2013a) Will mass drug administration eliminate lymphatic filariasis? Evidence from northern coastal Tanzania. Journal of Biosocial Science 45, 517-545.

Parker, M. \& Allen, T. (2013b) Questioning ethics in global health. In MacClancy, J. \& Fuentes, A. (eds) Ethics in the Field: Contemporary Challenges. Berghahn Press, Oxford, pp. 24-41.

Parker, M. \& Allen, T. (2014) De-politicising parasites: reflections on attempts to control the control of neglected tropical diseases in Uganda and Tanzania. Medical Anthropology 33(3), 223-239.

Parker, M., Allen, T. \& Hastings, J. (2008) Resisting control of neglected tropical diseases: dilemmas in the mass treatment of schistosomiasis and soil-transmitted helminths in north-west Uganda. Journal of Biosocial Science 40, 161-181.

Parker, M., Allen, T., Pearson, G., Peach, N., Flynn, R. \& Ress, N. (2012) Border parasites: schistosomiasis control among Uganda's fisherfolk. Journal of East African Studies 6(1), 98-123.

Pels, P. (1992) The white vampire: a neo-diffusionist analysis of rumour. Etnoforr 5, 165-187.

Pels, P. (1999) A Politics of Presence: Contacts between Missionaries and Walaguru in Late Colonial Tanganyika. Harwood Academic Publishers, The Netherlands.

Renne, E. P. (2010) The Politics of Polio in Northern Nigeria. Indiana University Press, Bloomington and Indianapolis.

Sanders, T. (2001) Save our skins: structural adjustment, morality and the occult in Tanzania. In Moore, H. L. \& Sanders, T. (eds) Magical Interpretations, Material Realities: Modernity, Witchcraft and the Occult in Postcolonial Africa. Routledge, London, pp. 160-183.

Savioli, L., Dixon, H., Kisumku, U. M. \& Mott, K. E. (1989) Control of morbidity due to Schistosoma haematobium on Pemba Island; selective population chemotherapy of schoolchildren with haematuria to identify high-risk localities. Transactions of the Royal Society of Tropical Medicine and Hygiene 83, 805-810.

SCI (2011) Schistosomiasis Control Initiative. URL: http://www.3imperial.ac.uk/schisto (accessed 11th May 2011).

Scott, J. (1985) Weapons of the Weak: Everyday Forms of Peasant Resistance. Yale University Press, New Haven and London.

UN-HABITAT (2009) Tanzania: Morogoro Profile. Regional and Technical Cooperative Division, UN-HABITAT, Kenya. 
Weiss, B. (1998) Electric vampires: Haya rumours of the commoodified body. In Lambek, M. \& Strathern, A. (eds) Bodies and Persons: Comparative Perspectives from Africa and Melanesia. Cambridge University Press, pp. 172-194.

White, L. (1995) Tsetse visions: narratives of blood and bugs in colonial northern Rhodesia, 1931-9. Journal of African History 36(2), 219-245.

White, L. (2000) Speaking with Vampires: Rumour and History in Colonial Africa. University of California Press, London.

WHO (2006) Preventive Chemotherapy in Human Helminthiasis: Coordinated Use of Anthelminthic Drugs In Control Interventions: A Manual for Health Professionals and Programme Managers. WHO Press, Geneva. URL: http://whqlibdoc.who.int/publications/ 2006/9241547103_eng.pdf?ua =1 (accessed 10th May 2015).

WHO (2012a) Schistosomiasis: A Major Public Health Problem. URL: http://www.who.int/ schistosomiasis/en/index.html (accessed 21st November 2012).

WHO (2012b) Best Days for Public Health are Ahead of us. Extract from address by Dr Margaret Chan, Director-General of the World Health Organization. URL: http://www.who.int/ neglected_diseases/dgspeech_may2012/en/(accessed 10th May 2015).

WHO (2014) Soil-Transmitted Helminth Infections. URL: http://www.who.int/mediacentre/ factsheets/fs366/en/ (accessed 1st October 2014).

Yahya, M. (2007) Polio vaccines - 'no thank you!' Barriers to polio eradication in northern Nigeria. African Affairs 106(423), 185-204.

Young, R. \& Fosbrooke, H. A. (1960) Smoke in the Hills: Political Tension in the Morogoro District on Tanganyika. Northwestern University Press, Evanston, IL. 